\title{
Preparation, Characterization, and Oxygen Barrier Properties of Regenerated Cellulose/Polyvinyl Alcohol Blend Films
}

\author{
Qianqian Zhu, ${ }^{\mathrm{a}, \mathrm{b}}$ Jingjing Wang, ${ }^{\mathrm{a}}$ Jianzhong Sun, ${ }^{\mathrm{a}, *}$ and Qianqian Wang ${ }^{\mathrm{a}, \mathrm{c}, \mathrm{d}, \mathrm{e}, \mathrm{f}, *}$
}

The application of cellulose materials for packaging usage has attracted a large amount of attention in recent years. In this study, cellulose was dissolved in a cold $\mathrm{NaOH} /$ urea solution. Transparent, strong, and flexible regenerated cellulose/polyvinyl alcohol (PVOH) films were fabricated via a solution blending and casting process. The physicochemical properties of the neat RC films, PVOH films, and RC-PVOH blend films were characterized via scanning electron microscopy, Fourier transform infrared spectroscopy, X-ray diffraction, thermogravimetric analysis, tensile tests, gas permeability, and ultraviolet-visible spectroscopy. The results of the physicochemical characterizations indicated that the RC$\mathrm{PVOH}$ composite films with various $\mathrm{PVOH}$ contents yielded strong properties in terms of optical transparency, thermal stability, mechanical strength, and oxygen barrier performance. The RC-PVOH films with $8 \%$ $\mathrm{PVOH}$ loading exhibited a peak degradation temperature of $362{ }^{\circ} \mathrm{C}$, a tensile strength of $80.8 \mathrm{MPa} \pm 0.3 \mathrm{MPa}$, and an oxygen permeability of $2.40 \mathrm{~cm}^{3} \times \mu \mathrm{m} / \mathrm{m}^{2} \times 24 \mathrm{~h} \times \mathrm{kPa}$. The RC-PVOH composite films could be a competitive alternative as a packaging material to replace petroleumbased plastics.

Keywords: Cellulose solution; Blend casting; Mechanical property; Oxygen permeability

Contact information: a: Biofuels Institute, School of the Environment and Safety Engineering, Jiangsu University, Zhenjiang 212013 China; b: Analysis and Testing Center, Jiangsu University, Zhenjiang, 212013 PR China; c: Hunan Province Key Laboratory of Engineering Rheology, Central South University of Forestry and Technology, Changsha 410004 China; d: Institute of Chemical Industry of Forest Products, Chinese Academy of Forestry; Key Laboratory of Biomass Energy and Material, Jiangsu Province, Nanjing 210042, China; e: State Key Laboratory of Pulp and Paper Engineering, South China University of Technology, Guangzhou 510640 China; f: State Key Laboratory of Bio-Fibers and Eco-Textiles, Qingdao University, Qingdao 266071 China;

* Corresponding authors: Email: jzsun1002@ujs.edu.cn (SJZ); qianqian.wz@ gmail.com (WQQ)

\section{INTRODUCTION}

Packing materials can provide effective barriers to light and oxygen, as well as to other chemicals, biological, and mechanical damage (Hubbe et al. 2017; Wang et al. 2018a). Petroleum-based plastics and synthetic plastic materials are ideal packaging materials, as the primary desirable features of plastic materials are their low cost, lightweight nature, easy processability, high stability and flexibility, and excellent physicochemical properties. However, plastic packaging materials are mostly permeable to gases and vapors, and thus they fail to prevent oxidation damage, which limits their application when impermeable barrier protection is required. In addition, considering the massive amount of plastic pollution, there has been a major increase in the interest of biodegradable polymers, e.g., cellulose, starch, chitosan, and polylactic acid (PLA). 
The development of environmentally friendly, renewable, and biodegradable cellulose-based packaging materials that also exhibit high transparency and excellent barrier properties has exponentially expanded, but there are still many challenges (Wang et al. 2018a). Cellulose-based packaging materials, e.g., regenerated cellulose films, surface-functionalized cellulose coatings, and cellulose nanocomposites, have been extensively investigated in order to improve the barrier strength and mechanical properties of paper and paperboard (Hubbe et al. 2017; Wang et al. 2018b; Zhu et al. $2020 \mathrm{a}, \mathrm{b})$. The application of thin coating layers of cellulose nanomaterials is a powerful tool for improving the mechanical and barrier properties of packaging materials. Spraying cellulose nanofibrils onto paper caused it to exhibit excellent oxygen barrier properties but increased its sensitivity to water vapor (Mirmehdi et al. 2018). As a low cost and nontoxic solvent, low-temperature $\mathrm{NaOH}$ /urea solution can dissolve cellulose with a high molecular weight $(114,000 \mathrm{~g} / \mathrm{mole})$ rapidly (Wang et al. 2016). The cellulose solutions can be kept stable for one week. The low-temperature $\mathrm{NaOH} /$ urea solvent is recognized as a milestone in the history of cellulose processing technology. Biodegradable cellulose copolymer films were prepared by the $\mathrm{NaOH}$ /urea method followed by coating with chitosan and $\mathrm{PVOH}$ solution. The prepared biocomposites exhibited good physical properties as potential packaging materials. The composition-process-structure-property relationship of the resulting biocomposites was systematically investigated (Cazón, et al. 2018a,b, 2019). Optical transparent regenerated cellulose films that had a high oxygen permeability $\left(0.003 \mathrm{~cm}^{3} \times \mu \mathrm{m} / \mathrm{m}^{2} \times 24 \mathrm{~h} \times \mathrm{kPa}\right.$ to $\left.0.03 \mathrm{~cm}^{3} \times \mu \mathrm{m} / \mathrm{m}^{2} \times 24 \mathrm{~h} \times \mathrm{kPa}\right)$ at $0 \%$ relative humidity $(\mathrm{RH})$ were prepared from $\mathrm{NaOH} /$ urea solutions (Yang et al. 2011a). To improve the moisture barrier properties of cellulose films, multiple studies have incorporated other polymers or fillers into the films (Wu et al. 2012; Wang et al. 2018a). As such, the mechanical and water barrier properties of the altered cellulose films have been substantially improved without undermining their original valuable properties (Wang et al. 2018a).

As a promising packaging material, $\mathrm{PVOH}$ is water-soluble, has high filmforming ability, is biodegradable, and is biocompatible, but has a relatively low mechanical strength and high water uptake capacity (Dalei et al. 2019). Thus, PVOH packaging materials may be applicable for usage as packaging for hot food products that require high water vapor permeability (Jain et al. 2018). Cellulose/PVOH based biocomposites have recently been fabricated via different strategies (Abdulkhani et al. 2013; Cazón et al. 2018a,b 2019). Homogeneous dispersion of cellulose and plastic polymer is a huge challenge. Solution blending is widely used to achieve a good dispersion. To our best knowledge, there has been a lack of research concerning RCPVOH composite films prepared by solution blending and casting. One such method, crosslinking, occurs when various crosslinking agents are introduced into the cellulose/PVOH composites.

Cellulose and PVOH, with their crystalline or semi-crystalline structures, could be interlinked via the hydrogen bonds between the hydroxyl groups. To take advantage of the properties of both cellulose and $\mathrm{PVOH}$, various ratios of cellulose and $\mathrm{PVOH}$ solutions were blended together in aqueous form. The main goal of this study was to evaluate regenerated cellulose (RC) and $\mathrm{PVOH}$ composites films prepared via solution casting for their potential application as a packaging material. First, the cellulose was dissolved in a cold $\mathrm{NaOH} /$ urea (aq) solution, and the PVOH was dissolved in hot water. A series of RC-PVOH composite films were produced by changing the ratios of the blending solutions of cellulose and PVOH. Flexible, transparent, and oxygen 
impermeable cellulose-based composite films were fabricated and characterized in the present study.

\section{EXPERIMENTAL}

\section{Materials and Chemicals}

Cotton linters with a viscosity average molecular weight of $1.07 \times 10^{5} \mathrm{~kg} \mathrm{~mol}^{-1}$ were obtained from Hubei Chemical Fiber Group Co., Ltd. (Xiangfan, China) and milled in a laboratory grinder to pass through a 40-mesh sieve. The flour obtained was ovendried and used in the subsequent experiments. The polyvinyl alcohol 124 (PVOH-124, DP 2400), sodium hydroxide, urea, and concentrated sulfuric acid were all purchased from Sinopharm Chemical Reagent Co., Ltd. (Shanghai, China) and used as received.

\section{Preparation of the RC Films and RC-PVOH Blend Films}

A $4 \%$ cellulose solution was prepared by dissolving $4 \mathrm{~g}$ of cellulose flour in $96 \mathrm{~g}$ of a precooled $\mathrm{NaOH}$ and urea solution (in a ratio of 7 parts $\mathrm{NaOH}$ to 12 parts urea to 81 parts deionized water, by wt $\%$ ) at $-12{ }^{\circ} \mathrm{C}$. The suspension was vigorously mixed for 5 min until a transparent solution was obtained. The air bubbles and small undissolved cellulose aggregates were then removed via centrifugation (Avanti-JE, Beckman Coulter, Brea, CA) at $8000 \mathrm{rpm}$ for $10 \mathrm{~min}$. A $4 \% \mathrm{PVOH}$ solution was prepared by dissolving $4 \mathrm{~g}$ of PVOH in $96 \mathrm{~g}$ of deionized water at $90{ }^{\circ} \mathrm{C}$ for $2 \mathrm{~h}$. The air bubbles were removed with an ultrasonic bath. The RC-PVOH composite films were produced by blending the cellulose and $\mathrm{PVOH}$ solutions at different ratios (100:0, 98:2, 95:5, 92:8, 90:10, and 0:100, which were labeled as RC, RC-PVOH2, RC-PVOH5, RC-PVOH8, RC-PVOH10, and $\mathrm{PVOH}$, respectively). The resulting transparent solutions were degassed and cast on a

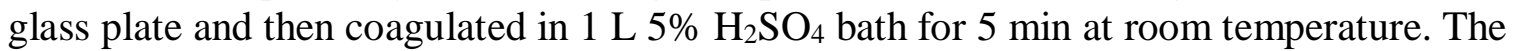
obtained hydrogel films were washed with deionized water until a neutral $\mathrm{pH}$ was reached, and then they were dried on a stainless steel plate at room temperature.

\section{Characterization}

The surface and cross-section morphologies of the RC-PVOH films were observed via scanning electron microscopy (S-3400N, Hitachi, Tokyo, Japan). The specimens were sputter-coated with a thin layer of gold and then loaded in the S-3400N SEM at a low acceleration voltage $(1 \mathrm{kV})$ for observation and photographing. The transmittance of the film was acquired from $200 \mathrm{~nm}$ to $800 \mathrm{~nm}$ using a DU-800 UV-Vis spectrophotometer (Beckman Coulter, Brea, CA), in triplicate. The final optical transmittance of the films was normalized with the thickness of the RC and RC-PVOH films of $0.036 \mathrm{~mm}$. Fourier-transform infrared spectroscopy (FTIR) experiments were performed with a Nicolet Nexus 470 FTIR spectrometer (Thermo Nicolet Corporation, Waltham, MA) in a region range of $4000 \mathrm{~cm}^{-1}$ to $500 \mathrm{~cm}^{-1}$ with a resolution of $4 \mathrm{~cm}^{-1}$. First, the composite films were ground into a fine powder in an agate mortar under a liquid nitrogen environment. The transparent pellets were then prepared by hydraulic pressing $2 \mathrm{mg}$ of the sample mixture with $200 \mathrm{mg}$ of $\mathrm{KBr}$ before FTIR viewing. Thermogravimetric analysis (TGA) of the films was performed with a Perkin Elmer TGA 4000 (PerkinElmer Inc., Waltham, MA) at a heating rate of $10{ }^{\circ} \mathrm{C}$ from $30{ }^{\circ} \mathrm{C}$ to $850{ }^{\circ} \mathrm{C}$ under nitrogen with a flow rate of $50 \mathrm{~mL} / \mathrm{min}$. Approximately $5 \mathrm{mg}$ of the sample was used in each run. The X-ray diffraction (XRD) patterns of the composite films were recorded using a D8 Advance diffractometer (Bruker, Billerica, MA) from $2 \theta=5^{\circ}$ to $2 \theta$ 
$=35^{\circ}$ at a scan speed of $2^{\circ} / \mathrm{min}$ at room temperature. The $\mathrm{CuK \alpha}$ radiation source was operated at $30 \mathrm{kV}$ and $15 \mathrm{~mA}$. The tensile strength was determined via a tensile tester (Model YG026MB, Fangyuan Instrument Co. Ltd., Wenzhou, China) with a $1000 \mathrm{~N}$ load cell at a speed of $5 \mathrm{~mm} / \mathrm{min}$ and at least 5 specimens were tested for each sample. The film oxygen permeability was measured using a VAC-V1 gas permeability tester (Labthink Instruments Co., Ltd., Boston, MA) according to standard GB/T1038 (2000). The oxygen permeability was determined at $23{ }^{\circ} \mathrm{C}, 0 \% \mathrm{RH}$, and with an area of $4.9 \mathrm{~cm}^{2}$ in triplicate. The oxygen permeability was normalized with the thickness of the film, and the corresponding oxygen permeability was reported in $\mathrm{cm}^{3} \times \mu \mathrm{m} / \mathrm{m}^{2} \times 24 \mathrm{~h} \times \mathrm{kPa}$.

\section{RESULTS AND DISCUSSION}

The images of the surface morphology of the blended films with various PVOH content are shown in Fig. 1a to Fig. 1e. As shown in the SEM images with different magnifications, i.e., $370 \mathrm{x}$ (Fig. 1e) to $3200 \mathrm{x}$ (Fig. 1b to Fig. 1d), all the films exhibit relatively flat surfaces. Figure 1a' to Fig. 1e' show the cross-sections of the neat RC film and the RC-PVOH blend films. The microfibril structures of the RC films could be clearly seen in Fig. 1a'. Relatively smooth cross-sections with voids were observed in the $\mathrm{RC}-\mathrm{PVOH}$ blend films, which was attributed to the incorporation of micro-scale $\mathrm{PVOH}$ fillers in the RC matrix. The SEM images of RC-PVOH2 and RC-PVOH5 reveal large cracks in the layered structures, whereas the image for the RC-PVOH8 film show relatively small and homogenously distributed voids. When the PVOH content increased to $10 \%$, the layered structure with larger cracks was observed again in the RC-PVOH10 blend films. This phenomenon could be attributed to the phase separation of the PVOH in the RC matrix (Cano et al. 2015).
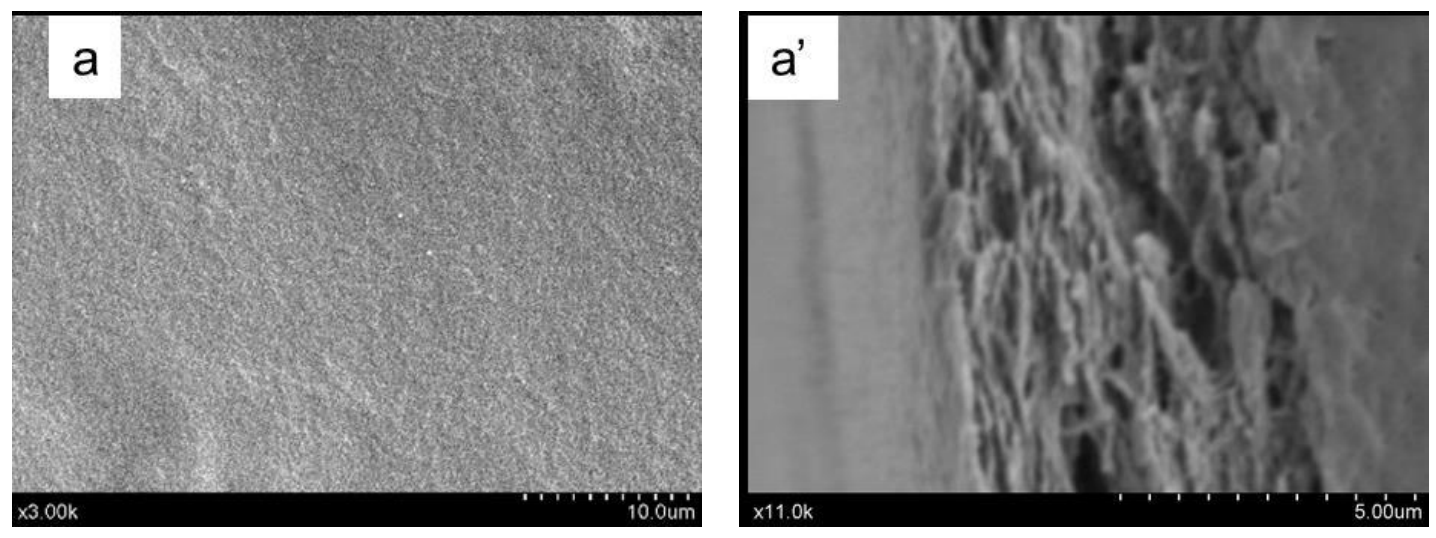

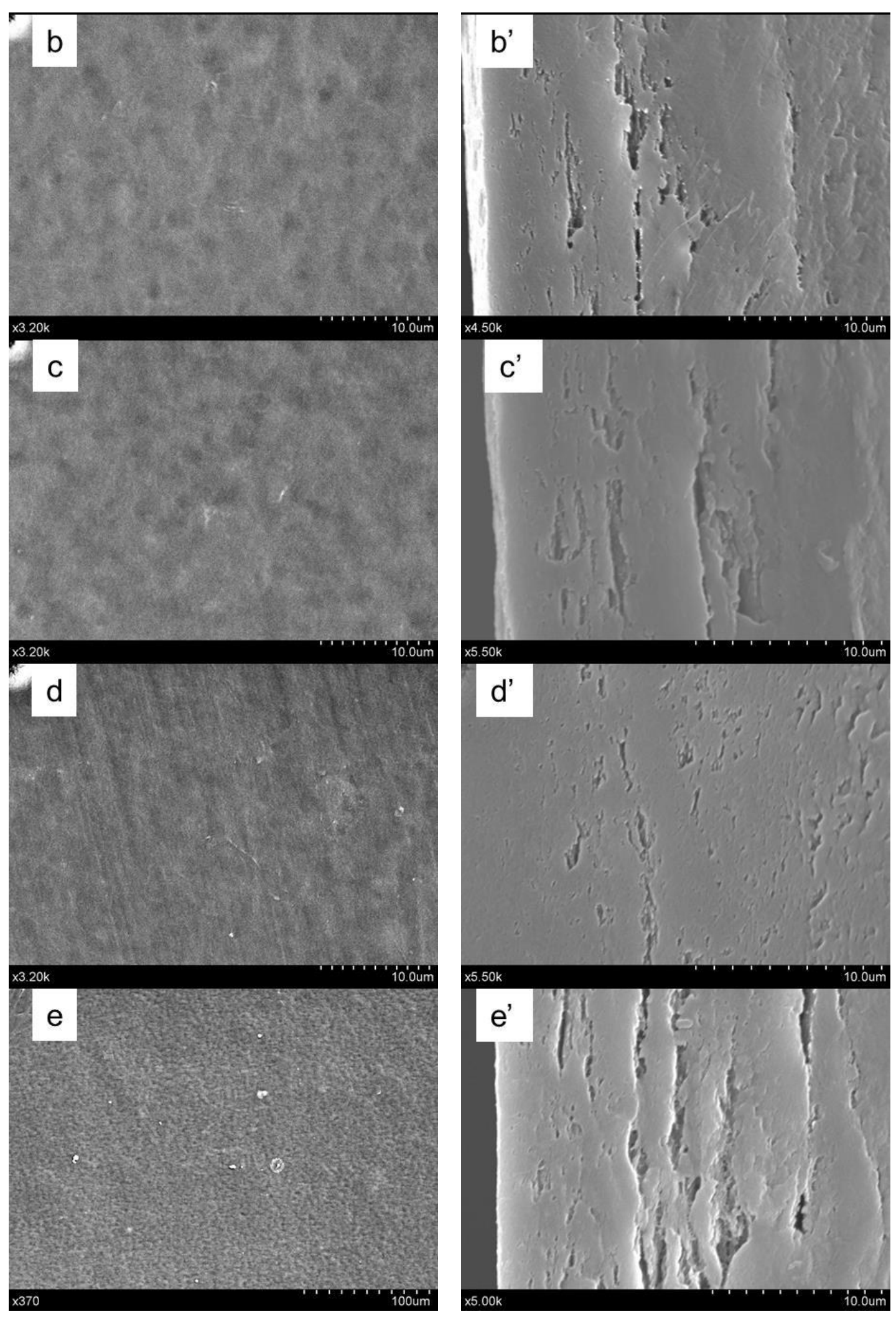

Fig. 1. SEM images of the surface and cross-sections of neat $R C$ film and RC-PVOH blend films: (a, a') RC; (b, b') RC-PVOH2; (c, c') RC-PVOH5; (d, d') RC-PVOH8; and (e, e') RC-PVOH10 
The adhesion that occurred between the $\mathrm{RC}$ and $\mathrm{PVOH}$ components enhanced the mechanical strength of the blend films. In summary, the concentration of PVOH could be an important parameter that affects the physio-chemical and structural properties of the RC-PVOH blend films.

The FTIR spectra of the neat RC film, PVOH film, and RC-PVOH composite films with various PVOH ratios are shown in Fig. 2a. The broad bands near $3430 \mathrm{~cm}^{-1}$ were assigned to the $\mathrm{O}-\mathrm{H}$ stretching, whereas the bonds at approximately $2900 \mathrm{~cm}^{-1}$ were assigned to the $\mathrm{C}-\mathrm{H}$ stretching in both the $\mathrm{RC}$ and $\mathrm{PVOH}$ films. The $\mathrm{O}-\mathrm{H}$ band tends to form hydrogen bonding, which is likely to affect the mechanical properties of the films (Cazón et al. 2019). The band at $2900 \mathrm{~cm}^{-1}$ reflects the change in the cellulose crystal structure (Abdulkhani et al. 2013). The absorption bands at $1720 \mathrm{~cm}^{-1}$ assigned to the $\mathrm{C}=\mathrm{O}$ bending vibration in the $\mathrm{PVOH}$ film were absent in the $\mathrm{RC}-\mathrm{PVOH}$ blend films, which was likely due to overlapping signals from the nearby $1630 \mathrm{~cm}^{-1} \mathrm{C}=\mathrm{O}$ stretching peak. Other characteristic bands were observed at $1165 \mathrm{~cm}^{-1}, 1060 \mathrm{~cm}^{-1}$, and $899 \mathrm{~cm}^{-1}$. The band at $1165 \mathrm{~cm}^{-1}$ was assigned to the C-O-C vibration. The bands at $1060 \mathrm{~cm}^{-1}$ and $899 \mathrm{~cm}^{-1}$ were recognized as the $\mathrm{C}-\mathrm{O}$ stretching and the $\mathrm{C}-\mathrm{H}$ deformation, respectively (Wang et al. 2015).

As shown in Fig. 2a, the ratio of PVOH in the film had little effect on the overall infrared spectra of RC-PVOH composite films, since the FTIR spectra of the cellulose and $\mathrm{PVOH}$ composites had strong overlapping signals. Although the interfacial interactions between cellulose and PVOH are still not fully understood, the abundance of hydroxyl groups of RC and PVOH suggests a tendency to form intermolecular hydrogen bonding. FTIR results indicated that there are no other chemical interactions between the cellulose and PVOH molecules besides hydrogen bonding (Abdulkhani et al. 2013; Voronova et al. 2015; Salehpour et al. 2018).
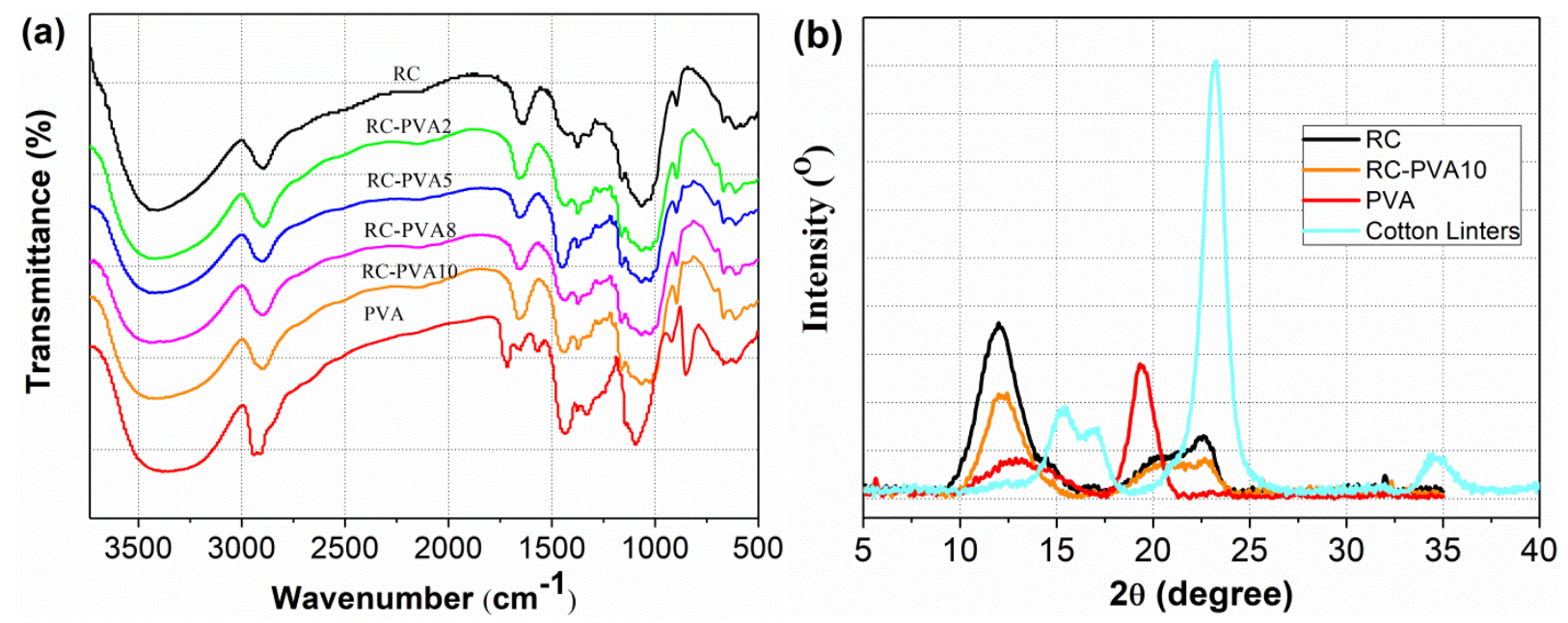

Fig. 2. The FTIR and XRD spectra: (a) the FTIR spectra of the RC film, RC-PVOH composite films, and PVOH film; (b) the X-ray diffractograms of the RC-PVOH10 film compared to the cotton linters, neat RC, and PVOH films

Figure $2 \mathrm{~b}$ shows the XRD patterns of the neat RC film, PVOH film, and RCPVOH blend films. The cotton linters had typical cellulose I diffraction peaks at $2 \theta=$ $15.4^{\circ}, 2 \theta=17.1^{\circ}$, and $2 \theta=23.2^{\circ}$ for $(1 \overline{1} 0),(110)$, and (200), respectively. Peaks at $2 \theta=$ $12.0^{\circ}, 2 \theta=20.0^{\circ}$, and $2 \theta=22.6^{\circ}$ were attributed to the $(1 \overline{1} 0),(110)$, and (020) plane for 
cellulose II ( $\mathrm{Li}$ et al. 2015; Qi et al. 2009). It was reported that cellulose I and II coexisted in the RC films regenerated from a $\mathrm{NaOH} /$ urea solution. It was noted that the $(1 \overline{1} 0)$ plane was stronger than the (110) and (200) peaks for cellulose II. This unusual phenomenon had previously been reported by Li et al. (2015) and Qi et al. (2009). The neat PVOH films exhibited two peaks at $2 \theta=12.9^{\circ}$ and $2 \theta=19.3^{\circ}$.

It was reported that the increase in $\mathrm{PVOH}$ content would decrease the cellulose crystallinity significantly (Zhang et al. 2012). On the other hand, the increase in cellulose content could also undermine the crystallinity of PVOH as reported by Lam, et al. (2017). The RC-PVOH blend films displayed a mixed diffraction pattern of characteristics from cellulose I, cellulose II, and PVOH.
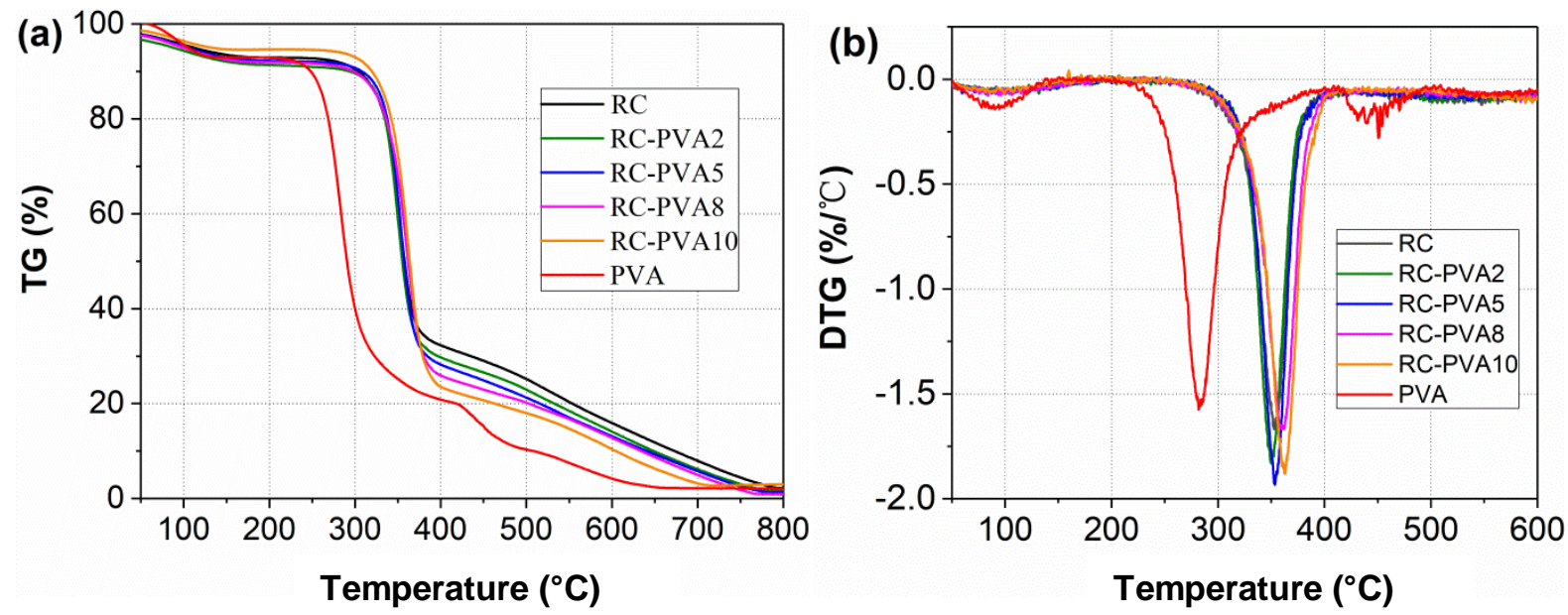

Fig. 3. The thermogravimetric analysis curves of the neat $\mathrm{PVOH}, \mathrm{RC}$, and $\mathrm{RC}-\mathrm{PVOH}$ blend films: (a) TGA curve; (b) DTG curve

A high level of thermal stability is critical for packaging materials under harsh thermal environments. Thermogravimetric analysis and DTG were used to evaluate the thermal decomposition of the RC-PVOH composite films, as shown in Figs. 3a and 3b. The thermal degradation of neat $\mathrm{PVOH}$ occurred in two stages; the first stage occurred at approximately $250{ }^{\circ} \mathrm{C}$ to $350{ }^{\circ} \mathrm{C}$ (approximately $70 \%$ of the initial weight), and the second stage occurred at approximately $420{ }^{\circ} \mathrm{C}$ to $600{ }^{\circ} \mathrm{C}$ (approximately $20 \%$ of the initial weight). Similar results were reported by Yang et al. (2011b). The maximum decomposition temperature of the neat $\mathrm{PVOH}$ was $282^{\circ} \mathrm{C}$. A two-stage decomposition was also observed for RC film at approximately $300{ }^{\circ} \mathrm{C}$ to $380{ }^{\circ} \mathrm{C}$ and at approximately $400{ }^{\circ} \mathrm{C}$ to $700{ }^{\circ} \mathrm{C}$, with a much higher peak temperature of $353{ }^{\circ} \mathrm{C}$, as shown in the DTG curve. It could be observed in Fig. 3 that no noticeable differences in the TGA and DTG curve shapes for the neat $\mathrm{RC}$ and $\mathrm{RC}-\mathrm{PVOH}$ blend films were detected at temperatures below $200{ }^{\circ} \mathrm{C}$. There were some visible differences between the neat $\mathrm{RC}$ film and the $\mathrm{RC}-\mathrm{PVOH}$ blend films when the temperature was higher than $400{ }^{\circ} \mathrm{C}$. The RC-PVOH blend films with a higher ratio of $\mathrm{PVOH}$ to $\mathrm{RC}$ had a relatively low residual mass. The $\mathrm{RC}-\mathrm{PVOH}$ composite films began to thermally decompose at temperatures greater than $300{ }^{\circ} \mathrm{C}$ (as shown in Fig. 3a). As the ratio of $\mathrm{PVOH}$ to $\mathrm{RC}$ increased in the composite films, so did the peak temperature of the derivative weight curve; the peak temperatures for RC-PVOH2, RC-PVOH5, RC-PVOH8, and RC-PVOH10 were $350{ }^{\circ} \mathrm{C}, 354{ }^{\circ} \mathrm{C}$, $362{ }^{\circ} \mathrm{C}$, and $363{ }^{\circ} \mathrm{C}$, respectively (as shown in Fig. $3 \mathrm{~b}$ ). The thermal decomposition 
process indicated that the thermal degradation temperatures of the RC-PVOH composite films were nearly identical to those of the neat RC film.

The tensile strength and oxygen permeability of the RC-PVOH films as functions of the ratio of PVOH to RC are shown in Figs. $4 \mathrm{a}$ and $4 \mathrm{~b}$, respectively. The neat $\mathrm{RC}$ film without PVOH had a tensile strength of $76.8 \mathrm{MPa} \pm 0.6 \mathrm{MPa}$. The structural defects, i.e., cracks and voids, in the blend composite films were decreased because of the increased ratio of $\mathrm{PVOH}$ to $\mathrm{RC}$. The tensile strength of the RC-PVOH composite films steadily increased from $77.1 \mathrm{MPa} \pm 1.1 \mathrm{MPa}$ to $80.8 \mathrm{MPa} \pm 0.3 \mathrm{MPa}$ as the PVOH content increased from $2 \%$ to $8 \%$. The increased tensile strength could also be related to the newly formed hydrogen bonds between the cellulose and PVOH molecules (Kondo and Sawatari 1998). The RC-PVOH8 film had the highest tensile strength. However, the addition of more PVOH (10\%) resulted in a noticeable reduction in tensile strength (79.9 $\mathrm{MPa} \pm 0.7 \mathrm{MPa}$ ), which is likely due to the possible agglomeration and inhomogeneous dispersion, as indicated by the SEM images. The structure defects led to poor interface interaction between PVOH and RC (Quero et al. 2018).
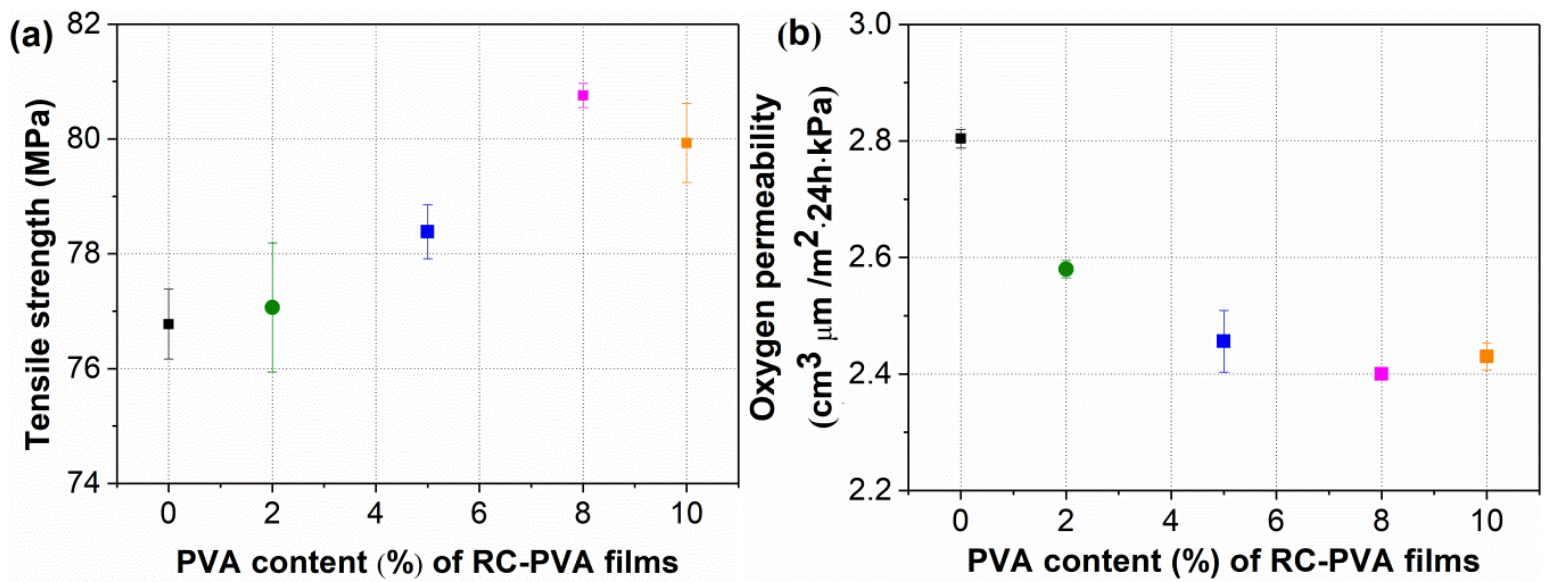

Fig. 4. The effect of the ratio of $\mathrm{PVOH}$ to $\mathrm{RC}$ on the tensile strength and oxygen permeability of RC-PVOH: (a) tensile strength; (b) oxygen permeability

Table 2. Oxygen Permeability of Cellulose or Starch Biocomposites

\begin{tabular}{|c|c|c|c|c|}
\hline Sample & $\begin{array}{c}\text { Composites } \\
\text { preparation }\end{array}$ & Humidity & $\begin{array}{c}\text { Oxygen permeability } \\
\mathrm{cm}^{3} \cdot \mu \mathrm{m} / \mathrm{m}^{2} \cdot 24 \mathrm{~h} \cdot \mathrm{kPa}\end{array}$ & Reference \\
\hline RC-PVOH8 & $\begin{array}{c}\text { Solution } \\
\text { blending and } \\
\text { casting }\end{array}$ & $0 \%$ & 2.4 & This study \\
\hline PLA30C & $\begin{array}{c}\text { melt-blending } \\
\text { and hot press }\end{array}$ & $65 \%$ & 72 & $\begin{array}{c}\text { (Battegazzore } \\
\text { et al. 2014) }\end{array}$ \\
\hline PA 6.10_5C & $\begin{array}{c}\text { melt-blending } \\
\text { and hot press }\end{array}$ & $50 \%$ & 18 & $\begin{array}{c}\text { Battegazzore } \\
\text { et al. 2018) }\end{array}$ \\
\hline $\begin{array}{c}\text { Thermoplastic } \\
\text { starch }\end{array}$ & $\begin{array}{c}\text { melt-blending } \\
\text { and hot press }\end{array}$ & $25 \%$ & 22 & $\begin{array}{c}\text { (Battegazzore } \\
\text { et al. 2015) }\end{array}$ \\
\hline
\end{tabular}

Figure $4 \mathrm{~b}$ shows the effect of the ratio of $\mathrm{PVOH}$ to $\mathrm{RC}$ on the oxygen permeability of the composite films. The oxygen permeability of the neat $\mathrm{RC}$ films at $0 \%$ RH was $2.80 \mathrm{~cm}^{3} \times \mu \mathrm{m} / \mathrm{m}^{2} \times 24 \mathrm{~h} \times \mathrm{kPa}$, while the oxygen permeability of the RC-PVOH

Zhu et al. (2020). "Regenerated cellulose-PVOH films," BioResources 15(2), 2735-2746. 2742 
composite films with a ratio of $\mathrm{PVOH}$ to $\mathrm{RC}$ ranging from $2 \%$ to $10 \%$ at $0 \% \mathrm{RH}$ steadily declined from $2.58 \mathrm{~cm}^{3} \times \mu \mathrm{m} / \mathrm{m}^{2} \times 24 \mathrm{~h} \times \mathrm{kPa}$ to $2.43 \mathrm{~cm}^{3} \times \mu \mathrm{m} / \mathrm{m}^{2} \times 24 \mathrm{~h} \mathrm{x} \mathrm{kPa} \mathrm{(as}$ shown in Fig. 4b). The RC-PVOH8 film had an even lower value $\left(2.40 \mathrm{~cm}^{3} \times \mu \mathrm{m} / \mathrm{m}^{2} \times 24\right.$ $\mathrm{h} \times \mathrm{kPa})$, which was considered in the high range $\left(40 \mathrm{~cm}^{3} \times \mu \mathrm{m} / \mathrm{m}^{2} \times 24 \mathrm{~h} \times\right.$ atm to 400 $\mathrm{cm}^{3} \times \mu \mathrm{m} / \mathrm{m}^{2} \times 24 \mathrm{~h} \times$ atm) (Wang et al. 2018a).

The oxygen permeability of the RC-PVOH composite films at $0 \% \mathrm{RH}$ was lower than the reported data by Syverud and Stenius (2008) for microfibrillated cellulose films $\left(3.52 \mathrm{~cm}^{3} \times \mu \mathrm{m} / \mathrm{m}^{2} \times 24 \mathrm{~h} \times \mathrm{kPa}\right.$ to $\left.5.03 \mathrm{~cm}^{3} \times \mu \mathrm{m} / \mathrm{m}^{2} \times 24 \mathrm{~h} \times \mathrm{kPa}\right)$, slightly higher than that of neat PVOH films (2.06 $\mathrm{cm}^{3} \times \mu \mathrm{m} / \mathrm{m}^{2} \times 24 \mathrm{~h} \times \mathrm{kPa}$ ) (Chen et al. 2017). The oxygen permeability of several biocomposites is listed in Table 2 . However, it was difficult to compare their oxygen permeability due to the different raw materials used, the processing methodologies, and testing conditions adopted.

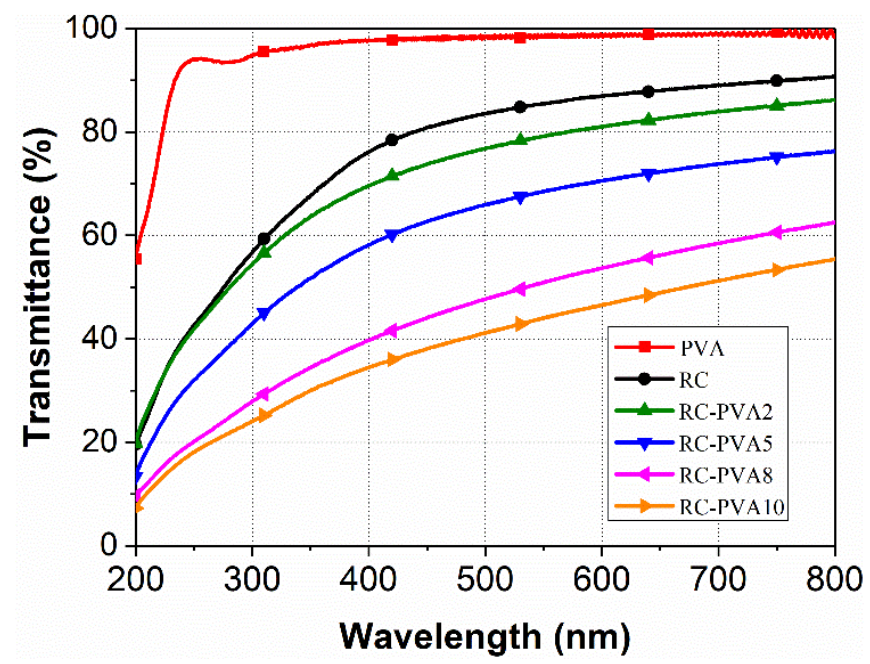

Fig. 5. The effect of the ratio of PVOH to RC on the transparency of the RC-PVOH films

Figure 5 displays the light transmittance of the pure PVOH film, RC film, and RC-PVOH films at a wavelength of $200 \mathrm{~nm}$ to $800 \mathrm{~nm}$. The obtained neat PVOH films showed excellent optical transparency with a mean value greater than $95 \%$ at a wavelength of $300 \mathrm{~nm}$ to $800 \mathrm{~nm}$. The transmittance value of the neat RC film was lower than the neat PVOH film. The ratio of $\mathrm{PVOH}$ to $\mathrm{RC}$ could be a vital factor in influencing the structure and transparency properties of the RC-PVOH blend films. Overall, the transmittance values of RC-PVOH blend films were much lower than the neat PVOH and RC films at the wavelength of $300 \mathrm{~nm}$ to $800 \mathrm{~nm}$, which indicated that the blending of $\mathrm{PVOH}$ with RC undermined the transparency of the blend films. The transmittance values decreased with the increase in PVOH proportions. Similar results were reported by Yuwawech et al. (2015) and Salehpour et al. 2018. The RC-PVOH10 film showed the lowest visible light transmittance values, which was still greater than $40 \%$ at a range of $400 \mathrm{~nm}$ to $750 \mathrm{~nm}$. This was probably due to the heterogeneous dispersion of $\mathrm{PVOH}$ and the formation of voids within the RC matrix, as revealed by the SEM. It was reported by Salehpour et al. (2018) that the surface roughness could also affect the light adsorption and transmittance values due to light scattering and the loss of the incident light intensity. 


\section{CONCLUSIONS}

1. The RC-PVOH composite films with different ratios of $\mathrm{PVOH}$ to $\mathrm{RC}$ were synthesized via a process of solution blending and casting.

2. The PVOH content was an important factor affecting the structural properties of the RC-PVOH films, as indicated by the SEM and UV-Vis spectra. The interactions between the RC and PVOH molecules were primarily physical interactions instead of chemical interactions.

3. The RC-PVOH films exhibited high levels of thermal stability, tensile strength, and oxygen permeability. The RC-PVOH composite film with $8 \% \mathrm{PVOH}$ displayed the best results, with a peak degradation temperature of $362{ }^{\circ} \mathrm{C}$, a tensile strength of 80.8 $\mathrm{MPa} \pm 0.3 \mathrm{MPa}$, and an oxygen permeability of $2.40 \mathrm{~cm}^{3} \times \mu \mathrm{m} / \mathrm{m}^{2} \times 24 \mathrm{~h} \times \mathrm{kPa}$.

\section{ACKNOWLEDGMENTS}

This work was funded by the National Key R\&D Program of China (2018YFE0107100), the Key Laboratory of Biomass Energy and Material of Jiangsu Province, Institute of Chemical Industry of Forest Products (JSBEM202012), State Key Laboratory of Bio-Fibers and Eco-Textiles, Qingdao University (K2019-18), State Key Laboratory of Pulp and Paper Engineering, South China University of Technology (202003), and Hunan Province Key Laboratory of Engineering Rheology (19HNKLE02), Central South University of Forestry Technology and PAPD.

\section{REFERENCES CITED}

Abdulkhani, A., Marvast, E. M., Ashori, A., Hamzeh, Y., and Karimi, A. N. (2013). "Preparation of cellulose/polyvinyl alcohol biocomposite films using 1-n-butyl-3methylimidazolium chloride," International Journal of Biological Macromolecules 62, 379-386. DOI: 10.1016/j.ijbiomac.2013.08.050

Battegazzore, D., Bocchini, S., Alongi, J., Frache, A. and Marino, F. (2014). "Cellulose extracted from rice husk as filler for poly(lactic acid): Preparation and characterization," Cellulose 21(3), 1813-1821. DOI: 10.1007/s10570-014-0207-5

Battegazzore, D., Bocchini, S., Nicola, G., Martini, E., and Frache, A. (2015). "Isosorbide, a green plasticizer for thermoplastic starch that does not retrogradate," Carbohydrate Polymers 119, 78-84. DOI: 10.1016/j.carbpol.2014.11.030

Battegazzore, D., Sattin, A., Maspoch, M.L., and Frache, A. (2018). "Mechanical and barrier properties enhancement in film extruded bio-polyamides with modified nanoclay," Polymer Composite 40(7), 2617-2628. DOI: 10.1002/pc.25056

Cano, A., Fortunati, E., Cháfer, M., González-Martinez, C., Chiralt, A., and Kenny, J. M. (2015). "Effect of cellulose nanocrystals on the properties of pea starch-poly(vinyl alcohol) blend films," Journal of Material Science 50(21), 6979-6992. DOI: 10.1007/s10853-015-9249-9

Cazón, P., Vázquez, M., and Velazquez, G. (2018a) "Composite films of regenerate cellulose with chitosan and polyvinyl alcohol: Evaluation of water adsorption, mechanical and optical properties," International Journal of Biological Macromolecules 117, 235-246. DOI: 10.1016/j.ijbiomac.2018.05.148 
Cazón, P., Vázquez, M., and Velazquez, G. (2018b). "Novel composite films based on cellulose reinforced with chitosan and polyvinyl alcohol: Effect on mechanical properties and water vapour permeability," Polymer Testing 69, 536-544. DOI: 10.1016/j.polymertesting.2018.06.016

Cazón, P., Velazquez, G., and Vázquez, M. (2019). "Novel composite films from regenerated cellulose-glycerol-polyvinyl alcohol: Mechanical and barrier properties," Food Hydrocolloid 89, 481-491. DOI: 10.1016/j.foodhyd.2018.11.012

Chen, C., Chen, Y., Xie, J., Xu, Z., Tang, Z., Yang, F., and Fu, K. (2017). "Effects of montmorillonite on the properties of cross-linked poly(vinyl alcohol)/boric acid films," Progress in Organic Coatings 112, 66-74. DOI: 10.1016/j.porgcoat.2017.06.003

Dalei, G., Das, S., Jena, S. R., Nayak, J., Samanta, L., and Das, S. P. (2019). "Surface modification of cellulose/polyvinyl alcohol biocomposites by non-thermal argon plasma: Applications towards biological relevance," Cellulose 26(4), 2437-2451. DOI: $10.1007 / \mathrm{s} 10570-019-02243-0$

GB/T 1038-2000 (2000). "Plastics - Film and sheeting - Determination of gas transmission - Differential-pressure method," Standardization Administration of China, Beijing, China.

Hubbe, M. A., Ferrer, A., Tyagi, P., Yin, Y., Salas, C., Pal, L. and Rojas, O. J. (2017). "Nanocellulose in thin films, coatings, and plies for packaging applications: A review," BioResources 12(1), 2143-2233. DOI: 10.15376/biores.12.1.2143-2233

Jain, N., Singh, V. K., and Chauhan, S. (2018). "A review on mechanical and water absorption properties of polyvinyl alcohol based composites/films," Journal of the Mechanical Behavior of Materials 26(5-6), 213-222. DOI: 10.1515/jmbm-2017-0027

Kondo, T., and Sawatari C (1998). "Interchain hydrogen bonds in cellulose-poly(vinyl alcohol) characterized by differential scanning calorimetry and solid-state nmr analyses using cellulose model compounds," in: Cellulose Derivatives: Modification, Characterization, and Nanostructures, T. J. Hienze, and W. G. Glasser (ed.), American Chemical Society, Washington, D.C., pp. 296-305. DOI: 10.1021/bk-19980688.ch021

Lam, N. T., Chollakup, R., Smitthipong, W., Nimchua, T., and Sukyai, P. (2017). "Utilizing cellulose from sugarcane bagasse mixed with poly(vinyl alcohol) for tissue engineering scaffold fabrication," Industrial Crops and Products 100, 183-197. DOI: 10.1016/j.indcrop.2017.02.031

Li, R., Wang, S., Lu, A., and Zhang, L. (2015). "Dissolution of cellulose from different sources in an $\mathrm{NaOH} /$ urea aqueous system at low temperature," Cellulose 22(1), 339349. DOI: 10.1007/s10570-014-0542-6

Mirmehdi, S., de Oliveira, M. L. C., Hein, P. R. G., Dias, M. V., Sarantópoulos, C. I. G. D., and Tonoli, G. H. D. (2018). "Spraying cellulose nanofibrils for improvement of tensile and barrier properties of writing \& printing (W\&P) paper," Journal of Wood Chemistry Technology 38(3), 233-245. DOI: 10.1080/02773813.2018.1432656

Qi, H., Cai, J., Zhang, L., and Kuga, S. (2009). "Properties of films composed of cellulose nanowhiskers and a cellulose matrix regenerated from alkali/urea solution," Biomacromolecules 10(6), 1597-1602. DOI: 10.1021/bm9001975

Quero, F., Padilla, C., Campos, V., Luengo, J., Caballero, L., Melo, F., Li, Q., Eichhorn, S. J., and Enrione, J. (2018). "Stress transfer and matrix-cohesive fracture mechanism in microfibrillated cellulose-gelatin nanocomposite films," Carbohydrate Polymers 195, 89-98. DOI: 10.1016/j.carbpol.2018.04.059 
Salehpour, S., Rafieian, F., Jonoobi, M., and Oksman, K. (2018). "Effects of molding temperature, pressure and time on polyvinyl alcohol nanocomposites properties produced by freeze drying technique," Industrial Crops and Products 121, 1-9. DOI: 10.1016/j.indcrop.2018.04.079

Syverud, K., and Stenius, P. (2008). "Strength and barrier properties of MFC films," Cellulose 16(1), 75-85. DOI: 10.1007/s10570-008-9244-2

Voronova, M. I., Surov, O. V., Guseinov, S. S., Barannikov, V. P., and Zakharov, A. G. (2015). "Thermal stability of polyvinyl alcohol/nanocrystalline cellulose composites," Carbohydrate Polymers 130, 440-447. DOI: 10.1016/j.carbpol.2015.05.032

Wang, Q., Wei, W., Kingori, G. P., and Sun, J. (2015). "Cell wall disruption in low temperature $\mathrm{NaOH} /$ urea solution and its potential application in lignocellulose pretreatment," Cellulose 22(6), 3559-3568. DOI: 10.1007/s10570-015-0767-z

Wang, S., Lu, A., and Zhang, L. (2016). "Recent advances in regenerated cellulose materials," Progress in Polymer Science 53, 169-206. DOI:

10.1016/j.progpolymsci.2015.07.003

Wang, J., Gardner, D. J., Stark, N. M., Bousfield, D. W., Tajvidi, M., and Cai, Z. (2018a). "Moisture and oxygen barrier properties of cellulose nanomaterial-based films," ACS Sustainable Chemistry \& Engineering 6(1), 49-70. DOI: 10.1021/acssuschemeng.7b03523

Wang, Q., Sun, J., Yao, Q., Ji, C., Liu, J., and Zhu Q. (2018b). “3D printing with cellulose materials," Cellulose 25(8), 4275-4301. DOI: 10.1007/s10570-018-1888-y

Wu, C.-N., Saito, T., Fujisawa, S., Fukuzumi, H., and Isogai, A. (2012). "Ultrastrong and high gas-barrier nanocellulose/clay layered composites," Biomacromolecules 16(3), 1927-1932. DOI: $10.1021 / \mathrm{bm} 300465 d$

Yang, H., Xu, S., Jiang, L., and Dan, Y. (2011b). "Thermal decomposition behavior of poly (vinyl alcohol) with different hydroxyl content," Journal of Macromolecular Science, Part B 51(3), 464-480. DOI: 10.1080/00222348.2011.597687

Yang, Q., Fukuzumi, H., Saito, T., Isogai, A., and Zhang, L. (2011a). “Transparent cellulose films with high gas barrier properties fabricated from aqueous alkali/urea solutions," Biomacromolecules 12(7), 2766-2771. DOI: 10.1021/bm200766v

Yuwawech, K., Wootthikanokkhan, J., and Tanpichai, S. (2015). "Effects of two different cellulose nanofiber types on properties of poly(vinyl alcohol) composite films," Journal of Nanomaterials 2015, 1-10. DOI: 10.1155/2015/908689

Zhang, X., Zhu, J., and Liu, X. (2012). "Preparation and characterization of regenerated cellulose blend films containing high amount of poly(vinyl alcohol) (PVOH) in ionic liquid," Macromolecular Research 20(7), 703-708. DOI: 10.1007/s13233-012-0106-2

Zhu, Q., Liu, S., Sun, J., Liu, J., Kirubaharan, C.J., Chen, H., Xu, W., and Wang, Q. (2020a). "Stimuli-responsive cellulose nanomaterials for smart applications," Carbohydrate Polymers 235, 115933. DOI: 10.1016/j.carbpol.2020.115933

Zhu, Q., Yao, Q., Sun, J., Chen, H., Xu, W., Liu, J., and Wang, Q. (2020b). "Stimuli induced cellulose nanomaterials alignment and its emerging applications: A review," Carbohydrate Polymers 230, 115609. DOI: 10.1016/j.carbpol.2019.115609

Article submitted: December 30, 2019; Peer review completed: February 22, 2020; Revised version received: February 25, 2020; Accepted; February 27, 2020; Published: March 2, 2020.

DOI: $10.15376 /$ biores.15.2.2735-2746 